Article

\title{
Improving Efficacy of Beauveria bassiana against Stored Grain Beetles with a Synergistic Co-Formulant
}

\author{
Clare Storm ${ }^{1, *}$, Freya Scoates ${ }^{1}$, Adam Nunn ${ }^{1}$, Olivier Potin ${ }^{2}$ and Aoife Dillon ${ }^{1}$ \\ 1 Exosect Ltd., Leylands Business Park, Colden Common, Winchester SO21 1TH, UK; \\ freya.scoates@exosect.com (F.S.); adam.nunn@myport.ac.uk (A.N.); aoife.dillon@exosect.com (A.D.) \\ 2 Agrauxine, 18 Route De Mauvieres, Loches 37600, France; olivier.potin@agrauxine.fr \\ * Correspondence: Clare.Storm@exosect.com; Tel.: +44-238-060-3940 \\ Academic Editors: Nickolas Kavallieratos, Christos Athanassiou, Vincenzo Palmeri and Orlando Campolo \\ Received: 19 July 2016; Accepted: 19 August 2016; Published: 26 August 2016
}

\begin{abstract}
The potential of a dry powder co-formulant, kaolin, to improve the control of storage beetles by the entomopathogenic fungus Beauveria bassiana, isolate IMI389521, was investigated. The response of Oryzaephilus surinamensis adults to the fungus when applied to wheat at $1 \times 10^{10}$ conidia per kg with and without kaolin at $1.74 \mathrm{~g}$ per $\mathrm{kg}$ wheat was assessed. Addition of kaolin increased control from $46 \%$ to $88 \%$ at day 7 and from $81 \%$ to $99 \%$ at day 14 post-treatment. Following this the dose response of $O$. surinamensis and Tribolium confusum to both kaolin and the fungus was investigated. Synergistic effects were evident against $O$. surinamensis at $\geq 0.96 \mathrm{~g}$ of kaolin per $\mathrm{kg}$ of wheat when combined with the fungus at all concentrations tested. For T. confusum, adult mortality did not exceed $55 \%$, however, the larvae were extremely susceptible with almost complete suppression of adult emergence at the lowest fungal rate tested even without the addition of kaolin. Finally, the dose response of Sitophilus granarius to the fungus at 15 and $25^{\circ} \mathrm{C}$, with and without kaolin at $1 \mathrm{~g}$ per $\mathrm{kg}$ of wheat, was examined. Improvements in efficacy were achieved by including kaolin at every fungal rate tested and by increasing the temperature. Kaolin by itself was not effective, only when combined with the fungus was an effect observed, indicating that kaolin was having a synergistic effect on the fungus.
\end{abstract}

Keywords: co-formulant; biopesticide; synergy; Beauveria bassiana; kaolin; entomopathogenic fungi

\section{Introduction}

Stored-product insects and mites cause serious post-harvest losses, estimated to range from $9 \%$ in developed countries to $20 \%$ or more in developing countries [1]. Pest infestations reduce the value of the commodity by contaminating it with insect fragments, faeces, webbing, and metabolic by-products [2]. The majority of grain stores and exporters have zero tolerance for pests and pesticide residues. Concerns over insecticide resistance, residues, and environmental impacts together with changes in legislation have led to a decline in available pesticides to protect stored food. Alternative pest control products are required to maintain levels of food production and anticipate future demand.

The use of entomopathogenic fungi such as Beauveria bassiana (Balsamo) Vuillemin (Hypocreales: Cordycipitaceae) and Metarhizium anisopliae (Metschinkoff) Sorokin (Hypocreales: Clavicipitaceae) to control stored product insects and mites has been explored extensively in laboratory and field scale trials [3-8]. Despite positive results, no microbial control agents based on entomopathogenic fungi are currently commercially available for grain storage. Perceptions that such products deliver lower efficacy than conventional chemical control measures may be one barrier to their commercialisation. These perceptions may be counteracted by improving the formulation and delivery of microorganisms. 
Inert dusts, such as mineral clays and silica powders, kill arthropods by removing the epicuticular lipid layers causing excessive water loss through the cuticle $[9,10]$. These dusts have been widely used for stored product pest control around the globe [11-13]. Of the inert dusts Diatomaceous earth (DE), a silica-based sedimentary rock, is the most widely used for storage protection and has been used commercially as a standalone preventative and curative treatment against stored product pests. DE demonstrates efficacy against a wide range of pests [14-17], but its widespread adoption has been hampered based on a number of perceived drawbacks: (1) its effectiveness varies widely depending on target species and life stage, humidity, and temperature [14,15,18], (2) problems with processing machinery maintenance \& damage [10], and (3) reductions in grain quality parameters such as bulk density and flowability $[19,20]$. Kaolin, an alternative inert dust, is a common, silica-based clay mineral used in industrial manufacturing [21]. It is a siliceous mineral similar to, but softer than, DE; it scores relatively low (2.0-2.5) on Mohs hardness index, making it less likely to abrade milling equipment (Campden BRI, pers. comm). Kaolin has demonstrated effectiveness on stored product insects [22,23] but requires very high application rates in admixture with grain (5-10 g per $\mathrm{kg}$ of grain) when used as a standalone product $[10,24]$. Such inclusion rates would have an unacceptable impact on grain quality parameters such as appearance, bulk density and flowability. However, as with DE, there may be the potential to reduce application rates if it can be coupled with another active ingredient.

Several studies have demonstrated that inert dusts can be used as a carrier of microbial control agents in stored product protection. In the case of DE additive [25-28], and sometimes synergistic effects [6,29,30], have been observed. Lord (2001) [29] found that when B. bassiana was co-formulated with DE a synergistic effect was observed against the sawtoothed grain beetle, Oryzaephilus surinamensis (L.) (Coleoptera: Silvanidae), the lesser grain borer, Rhyzopertha dominica (F.) (Coleoptera: Bostrichidae) and the rusty grain beetle, Cryptolestes ferrugineus (Stephens) (Coleoptera: Laemophloeidae). Akbar et al. (2004) [30] also recorded a synergistic effect when testing the same combination against Tribolium castaneum (Herbst) (Coleoptera: Tenebrionidae) larvae. Sabbour et al., (2012) [6] tested M. anisopliae and B. bassiana isolates against storage moths Plodia interpunctella Hübner (Lepidoptera: Pyralidae), Ephestia cautella Walker (Lepidoptera: Pyralidae), and Ephestia kuehniella Zeller (Lepidoptera: Pyralidae) and found that, in most cases, DE had a synergistic effect when combined with the fungi. Improvements in efficacy against storage pests have also been reported when $M$. anisopliae [26,27] and Paecilomyces fumosoroseus (Wise) Brown and Smith (Eurotiales: Trichocomaceae) [28] were combined with DE, compared to when the fungus was applied alone. There are fewer examples where the combination of an entomopathogenic fungus with the inert dust kaolin has been tested on storage pests. Samodra \& Ibrahim (2006a, b) [31,32] found that B. bassiana formulated in kaolin was more efficacious against larvae of the rice moth, Corcyra cephalonica Stainton (Lepidoptera: Pyralidae) and adult Sitophilus oryzae (L.) (Coleoptera: Curculionidae), than when the fungus was formulated in tapioca flour or unformulated.

In this study, we evaluated the ability of kaolin to enhance the activity of $B$. bassiana, isolate IMI389521, against stored grain beetles in a series of bioassays. Our hypothesis was that the presence of kaolin would increase the pathogenicity of the fungus to the target insects. A variety of adult beetles were tested to determine if any effect of kaolin was species-dependent. As test insects we used three major stored product beetle species with varying susceptibility to the fungus: the saw-toothed grain beetle O. surinamensis, the granary weevil S. granarius, and the relatively tolerant [32] confused flour beetle Tribolium confusum Jacquelin du Val (Coleoptera: Tenebrionidae). Sitophilus granarius is a primary pest, infesting intact kernels, while T. confusum and O. surinamensis are secondary pests, infesting only damaged or broken kernels [33] and processed grain such as flour. Additionally, due to the relatively low levels of mortality observed on adult T. confusum, the response of the larvae, which have been shown to be more susceptible to entomopathogenic fungi than the adults [26,30], were also tested. 


\section{Materials and Methods}

\subsection{Test Insects}

All adult insects were taken from laboratory maintained cultures. The O. surinamensis individuals were reared on rolled oats and wheat germ in a ratio of $3: 1 w / w$ at $27 \pm 2{ }^{\circ} \mathrm{C}$ and $40 \% \pm 5 \%$ relative humidity (RH). The T. confusum adults were maintained on a diet of rolled porridge oats and brewer's yeast in a ratio of 9:1 $w / w$ at $30 \pm 2{ }^{\circ} \mathrm{C}$ and $40 \% \pm 5 \% \mathrm{RH}$. Adult $S$. granarius were reared on kibbled wheat grain and wheat germ in a ratio of $19: 1 w / w$ at $25 \pm 2{ }^{\circ} \mathrm{C}$ and $65 \% \pm 5 \% \mathrm{RH}$. All insects were reared in continuous darkness. Adult beetles of mixed age and sex were used for testing.

For the larval bioassay (bioassay 3) all of the early instar T. confusum larvae required were supplied in diet from i2L Research (Cardiff, UK).

\subsection{Test Items}

The isolate of B. bassiana IMI389521 was originally sourced from an infected adult coleopteran S. oryzae in a UK grain store [5] and had previously demonstrated efficacy against a variety of storage insects, good stability in storage, and high levels of viability following mass-production [34,35]. The isolate was manufactured by Agrauxine (Loches, France). The dry conidia were combined with co-formulants at Exosect Ltd. (Winchester, UK) to make the various formulations. In bioassay 1 one the $B$. bassiana quantities are expressed as total conidia per $\mathrm{kg}$ of wheat but in subsequent bioassays, due to a change in quality control procedures by the manufacturer, the quantities are expressed as colony forming units (CFU) per kg wheat. Kaolin clay (AgriBind ${ }^{\mathrm{TM}}$ ) was supplied by Imerys (Par, Cornwall, UK). In the S. granarius experiment, bioassay 4, the conidia were also combined with Entostat ${ }^{\circledR}$ to aid dispersion and adhesion to grain and insects, and silica to aid flow. The Entostat variant used was micronized carnauba wax supplied by Exosect Ltd. and Sipernat d17 was supplied by Lawrence Industries (Tamworth, UK).

\subsection{Commodity}

Residue-free wheat was supplied from Street End Farm (Bishops Waltham, UK) and kibbled for $30 \mathrm{~s}$ in a coffee grinder, except for the S. granarius bioassay (bioassay 4), where residue-free wheat grain var. Alderon was supplied by KWS UK (Royston, UK) and was not kibbled.

Grain used in bioassay three and four was stored in paper bags in $500 \mathrm{~g}$ samples and placed in a humidity-controlled incubator (TK 252, Nüve, Ankara, Turkey)) for one week before the bioassays in order to equilibrate the grain to the test conditions.

\subsection{Bioassay 1: Initial Testing of O. surinamensis}

The response of $O$. surinamensis adults to $B$. bassiana IMI389521 at $1 \times 10^{10}$ conidia per $\mathrm{kg}$ of wheat was tested with and without kaolin admixed at a rate of $1.74 \mathrm{~g}$ per $\mathrm{kg}$ of wheat. Kaolin without B. bassiana and an untreated control were included for comparison. Fifty grams of kibbled wheat were weighed into $125 \mathrm{~mL}$ glass jars and treatments were added on top. The jars were covered and placed on a vortex mixer for $10 \mathrm{~s}$ to disperse the treatments. Five replicate jars were created for each treatment. Twenty adult $O$. surinamensis were added to each jar and the jars were covered with a piece of gauze held in place with an elastic band. Jars were arranged on a shelf in a bioassay room set to constant darkness (except during mortality checks) and $25 \pm 3{ }^{\circ} \mathrm{C}$. Humidity was monitored throughout the trial with a Lascar data logger and found to range from $47 \%$ to $62 \% \mathrm{RH}$.

At days 7 and 14 the contents of each pot were individually tipped onto a white plastic tray and the insects were checked for mortality. Dead beetles were removed. Live beetles, grain, and powder were tipped back into the pots, except at the final time point. Trays were sterilized with $70 \%$ ethanol between treatments. 


\subsection{Bioassay 2: Dose Response of O. surinamensis}

The response of $O$. surinamensis adults to different rates of B. bassiana IMI389521 and kaolin was tested. The fungus was applied at five rates: $0,5.4 \times 10^{8}, 1.7 \times 10^{9}, 5.4 \times 10^{9}$, and $1.7 \times 10^{10} \mathrm{CFU}$ per $\mathrm{kg}$ of wheat, and for each rate of fungus the kaolin was tested at one of four rates: 0, 0.096, 0.963, and $1.925 \mathrm{~g}$ per $\mathrm{kg}$ of wheat, resulting in 20 treatment groups in total.

For each bioassay and treatment group $250 \mathrm{~g}$ of kibbled wheat was weighed into a 1 L glass Kilner jar and treatments were added on top. The jars were rolled by hand for $30 \mathrm{~s}$ to disperse the treatments. The grain was then subdivided into five replicate $125 \mathrm{~mL}$ glass jars. Twenty adult $O$. surinamensis were added to each jar and the jars were covered with a piece of gauze held in place with an elastic band. Jars were arranged in a humidity controlled incubator set to $25 \pm 2{ }^{\circ} \mathrm{C}$ and $65 \% \pm 5 \% \mathrm{RH}$ in constant darkness. At day 14, the insects were checked for mortality.

\subsection{Bioassay 3: Dose Response of T. confusum Adults and Larvae}

The response of T. confusum adults and larvae to different rates of B. bassiana IMI389521 and kaolin was tested. The response of T. confusum was assessed at higher rates of B. bassiana than of O. surinamensis, as the adults are less susceptible to the fungus than the other beetles tested [34]. In addition, lower concentrations of kaolin were assessed in the T. confusum bioassays as the highest rate (1.925 g per $\mathrm{kg}$ of wheat) was subsequently considered to be not commercially viable. The fungus was applied at five rates: $0,1.78 \times 10^{10}, 3.16 \times 10^{10}, 5.62 \times 10^{10}$, and $1 \times 10^{11} \mathrm{CFU}$ per $\mathrm{kg}$ of wheat in both bioassays. In the adult bioassay, for each rate of fungus the kaolin was applied at one of five rates: $0,0.178,0.316,0.562$, and $1 \mathrm{~g}$ per $\mathrm{kg}$ of wheat resulting in 25 treatment groups in total. In the larval bioassay, kaolin was tested at either 0 or $0.562 \mathrm{~g}$ per $\mathrm{kg}$ of wheat, resulting in ten treatment groups in total.

In the adult bioassay, the grain was treated, sub-divided, and insects added as per Section 2.5. In the larval bioassay, it was not possible to count out larvae for each replicate jar so the container of larvae in diet, with an estimated content of 2500 larvae, was homogenized by gently rolling for $30 \mathrm{~s}$ and then subdivided by weight into ten samples, one for each treatment group. The treatments were applied to the grain as per Section 2.5 and then the larvae were added before sub-dividing the mixture into five replicate jars. Assuming a homogenous mixture of larvae in diet, this should have resulted in approximately 250 larvae per treatment group and then 50 larvae per replicate jar. The jars in both bioassays were stored as per Section 2.5.

At day 14, the adult insects were checked for mortality as detailed in Section 2.4. At day 42, the jars from the larval bioassay were checked for adult emergence.

\subsection{Bioassay 4: Dose Response of S. granarius and the Effect of Temperature}

The response of S. granarius adults to different rates of B. bassiana IMI389521 with and without kaolin at $1 \mathrm{~g}$ per $\mathrm{kg}$ wheat was assessed. The fungus was applied at four rates: $0,1.78 \times 10^{9}, 5.62 \times 10^{10}$, and $1.78 \times 10^{10} \mathrm{CFU}$ per $\mathrm{kg}$ wheat. For each of the formulations containing the fungus, a flow agent, (Sipernat d17) and Entostat, were also added. Sipernat d17 was added as $0.5 \% w / w$ of the total quantity of formulation to be applied. The balance of the formulation was made up of Entostat, which was added to the dry conidia before mixing with the kaolin. Details of the treatments, application rates and quantities of components are given in Table 1. An untreated control and kaolin-only treatment were also assessed. Mortality was examined 14 and 28 days after incubation at either 15 or $25^{\circ} \mathrm{C}$, resulting in 32 treatment combinations in total.

For each treatment combination, $500 \mathrm{~g}$ of equilibrated wheat was treated in a $1 \mathrm{~L}$ glass Duran bottle by adding the formulation on top of the grain and then rolling the jar using a bottle roller for $3 \mathrm{~min}$ to ensure even distribution of the treatment. The wheat was then subdivided into ten $125 \mathrm{~mL}$ glass jars each containing $50 \mathrm{~g}$ of grain. Fifteen $S$. granarius adults were added to each jar. To prevent 
the insects from escaping, the tops of the jars were covered with a square of gauze which was retained in position with an elastic band.

Table 1. Details of the application rates and quantities of formulation components used in the Sitophilus granarius bioassay (bioassay 4).

\begin{tabular}{cccccc}
\hline Formulation Applied & Rate of Conidia Applied & \multicolumn{3}{c}{ Amount in Formulation (g per kg) } \\
\cline { 3 - 5 } to Wheat (g per kg) & to Wheat (CFU per kg) & Fungal Conidia & Kaolin & Entostat & Sipernat d17 \\
\hline 0.0507 & $1.78 \mathrm{E}+9$ & 350 & 0 & 645 & 5 \\
0.1606 & $5.62 \mathrm{E}+10$ & 350 & 0 & 645 & 5 \\
0.5086 & $1.78 \mathrm{E}+10$ & 350 & 0 & 645 & 5 \\
1.0509 & $1.78 \mathrm{E}+9$ & 16.9 & 951.6 & 26.5 & 5 \\
1.1605 & $5.62 \mathrm{E}+10$ & 48.4 & 861.6 & 84.9 & 5 \\
1.5086 & $1.78 \mathrm{E}+10$ & 118 & 662.9 & 214.1 & 5 \\
\hline
\end{tabular}

Jars were arranged in one of two humidity controlled incubators set to constant darkness and $65 \% \pm 5 \%$ RH. One incubator was set to $15 \pm 2{ }^{\circ} \mathrm{C}$ and the other to $25 \pm 2{ }^{\circ} \mathrm{C}$. At day 14 , ten of the jars from each temperature $\times$ kaolin $\times$ fungal rate combination were randomly selected and the insects assessed as detailed in Section 2.4. The remaining jars were checked at day 28.

\subsection{Statistical Analysis}

For bioassay 1, the mortality data were found to deviate significantly from a normal distribution even after data transformation. As a result, the proportions data for each time point were analysed with a Kruskal-Wallis test followed by pairwise comparisons with a two-way Dunn's procedure. Analyses were performed using XLSTAT (version 2014.1.01.; Addinsoft, Paris, France, 2014).

For bioassay 2 and 3, the mortality data were found to deviate significantly from a normal distribution, even after data transformations. For each bioassay, logistic regression (probit) was used to model the impact of fungal rate on mortality for each rate of kaolin that was tested. The dose variable was converted to a logarithmic scale before analysis. Each regression profile was then used to find the concentration of spores required to achieve the LC50 at each level of kaolin tested. The LC50 was calculated for doses that adequately fit the probit model and assessed using a $\chi^{2}$ goodness-of-fit test $(p>0.1$ indicates a good fit). The analyses were done using the "Dose" add-in for XLSTAT (version 2014.1.01).

For bioassay 4 , the S. granarius mortality data were found to deviate significantly from a normal distribution even after data transformations. As a result, the proportions data were used to construct a fully factorial Generalised Linear Model (GLM). An ANOVA was applied to the results of the GLM to look for significant effects. Due to overdispersal of residuals, quasibinomial errors were used. Analysis was carried out using R software (version 3.1.0.; The R Foundation for Statistical Computing, Vienna, Austria, 2014). As for bioassay 2 and 3, logistic regression (probit) was used to model the impact of fungal rate on mortality with or without kaolin, at each temperature, using the "Dose" add-in for XLSTAT (version 2014.1.01.).

\section{Results}

\subsection{Bioassay 1: Initial Testing of O. surinamensis}

The effect of treatment was significant for both the day 7 and day 14 mortality data $(p=0.001$ for both). After $7 \mathrm{~d}$, most of the beetles in the combined treatment were already dead (>88\%) (Figure 1) with significantly higher mortality compared to the untreated control and kaolin-only treatments $(p<0.001$ and $p=0.004$ respectively), where mortality did not exceed $22 \%$. At day 14 , mortality reached $99 \%$ in the combined treatment, and was again significantly different than that of the untreated control and kaolin-only groups, $(p<0.001$ and $p=0.003$ respectively), where mortality did not exceed 28\%. Although mortality in the fungus only treatment (day 7: 46\% and day 14: $81 \%$ ) 
was less than in the combined treatment, the difference between these groups was not significant ( $p=0.139$ and $p=0.174$, respectively); possibly owing to the fact that the data were analysed by non-parametric methods and the low number of replications $(n=5)$.

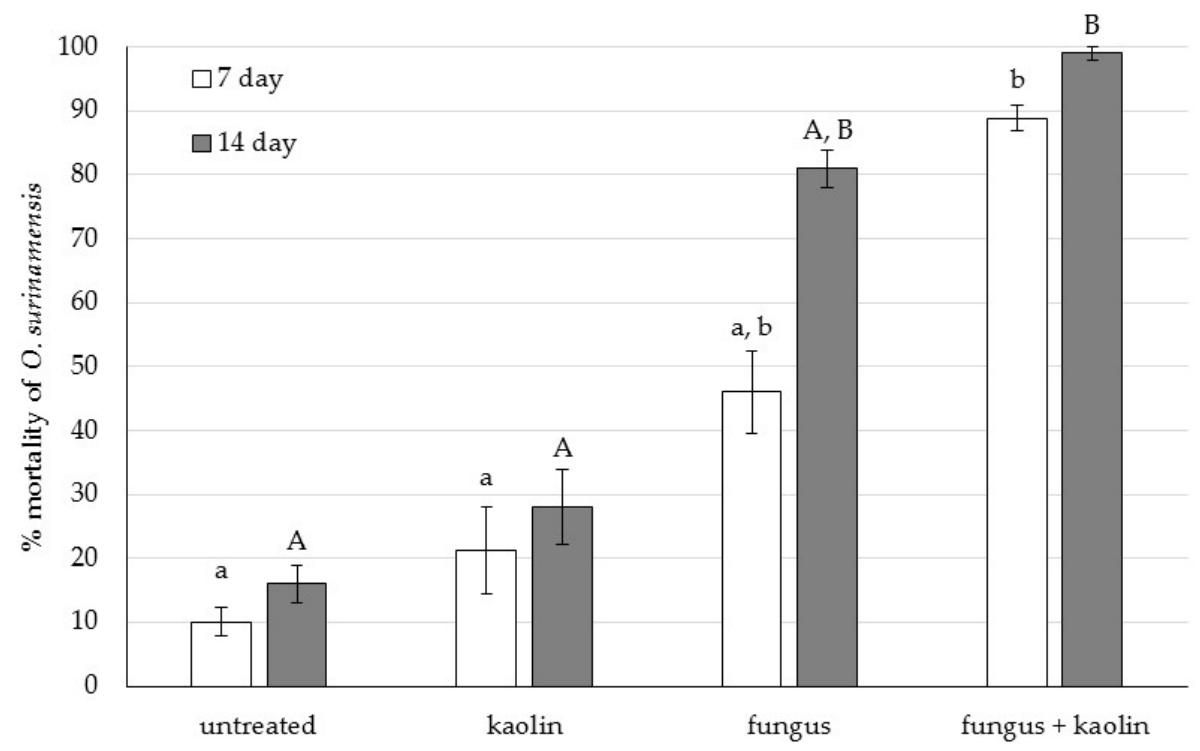

Figure 1. Bioassay 1: Percentage mortality of Oryzaephilus surinamensis adults exposed to Beauveria bassiana IMI389521 at $1 \times 10^{10}$ conidia per $\mathrm{kg}$ of wheat, kaolin at $1.74 \mathrm{~g}$ per $\mathrm{kg}$ of wheat, and a combination of the two, after 7 and 14 days of exposure (Mean \pm SE). Different letters between groups within time points denote statistical difference among treatments $(p \leq 0.004)$.

\subsection{Bioassay 2: Dose Response of O. surinamensis}

The treatments with the most kaolin $(1.9253 \mathrm{~g}$ per $\mathrm{kg}$ of wheat) consistently achieved the highest level of mortality (>90\%) when combined with fungus at a rate of at least $1.7 \times 10^{9} \mathrm{CFU}$ per $\mathrm{kg}$ of wheat or more (Figure 2). The fungus alone never killed more than $50 \%$ of the insects, even at the highest rate $\left(1.7 \times 10^{10} \mathrm{CFU}\right.$ per $\mathrm{kg}$ of wheat). Kaolin alone may have exerted an effect at a rate of $1.9253 \mathrm{~g}$ per $\mathrm{kg}$ of wheat with mortality at $13 \%$ compared to $0 \%$ in the untreated control, but this was not tested statistically. Treatments of the fungus with the lowest level of kaolin $(0.0963 \mathrm{~g}$ per $\mathrm{kg}$ of wheat) exhibited similar levels of mortality to the fungus alone. However, when the kaolin was combined with the fungus at 0.9626 or $1.9253 \mathrm{~g}$ per $\mathrm{kg}$ of wheat, the level of mortality compared to fungus alone was more than doubled in most treatment groups. At the lowest rate of fungus, $5.4 \times 10^{8} \mathrm{CFU}$ per $\mathrm{kg}$ of wheat, the increase when combined with the highest rate of kaolin was more than seven-fold.

Logistic regression was carried out on the mortality data for each rate of kaolin and was found to adequately fit the probit model (Table 2). The LC50 for fungal rate decreased as the rate of kaolin increased. The LC50 was $>12$ times lower when kaolin was included at a rate of $0.9629 \mathrm{~g}$ per $\mathrm{kg}$ of wheat and $>44$ times lower when it was included at the highest rate of $1.9253 \mathrm{~g}$ per $\mathrm{kg}$ of wheat.

\subsection{Bioassay 3: Dose Response of T. confusum Adults and Larvae}

Mortality did not exceed $55 \%$ in any of the treatment groups and above $27 \%$ in all groups which contained fungus (Figure 3). In the treatments with no fungus mortality did not exceed 5.2\%, even at the highest level of kaolin ( $1 \mathrm{~g}$ per $\mathrm{kg}$ of wheat). Kaolin appeared to have very little effect, if any, on mortality, even when combined with fungus. The fungal isolate seemed to exert some efficacy as mortality was higher than in the untreated groups but there was no clear dose response at the range tested (Table 3). The data was a poor fit for the probit model in each case. The LC50 for fungal rate was found to decrease as the rate of kaolin increased but there was little difference between the top 
and bottom rate with overlapping 95\% confidence interval (CI). Neither kaolin rate nor spore rate in the range tested made a large difference to the level of mortality.

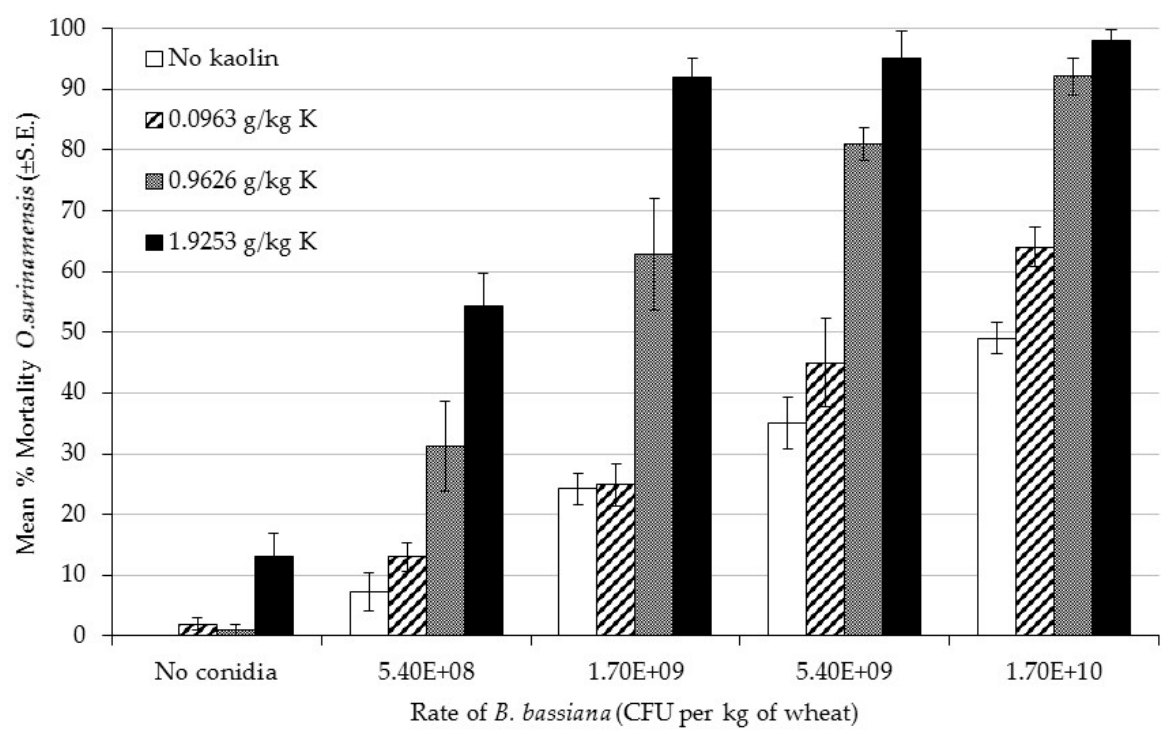

Figure 2. Bioassay 2: Percentage mortality of Oryzaephilus surinamensis adults exposed to different rates of Beauveria bassiana IMI389521 and different rates of kaolin after 14 days of exposure (Mean \pm SE).

Table 2. Results of logistic regression on Oryzaephilus surinamensis mortality data for each rate of kaolin in dose response bioassay 2.

\begin{tabular}{ccccccc}
\hline $\begin{array}{c}\text { Rate of Kaolin } \\
\text { (g per kg of Wheat) }\end{array}$ & $\begin{array}{c}\text { LC50 (CFU per kg } \\
\text { of Wheat) }\end{array}$ & $\begin{array}{c}\text { Lower } \\
\text { Bound 95\% }\end{array}$ & $\begin{array}{c}\text { Upper } \\
\text { Bound 95\% }\end{array}$ & $\mathbf{R}^{\mathbf{2}}$ & $\chi^{\mathbf{2}}$ & $p$-Value \\
\hline 0 & $1.582 \mathrm{E}+10$ & $1.008 \mathrm{E}+10$ & $3.230 \mathrm{E}+10$ & 0.099 & 47.541 & $<0.0001$ \\
0.0963 & $7.47 \mathrm{E}+09$ & $5.43 \mathrm{E}+09$ & $1.13 \mathrm{E}+10$ & 0.129 & 67.925 & $<0.0001$ \\
0.9626 & $1.228 \mathrm{E}+09$ & $8.752 \mathrm{E}+08$ & $1.606 \mathrm{E}+09$ & 0.202 & 96.657 & $<0.0001$ \\
1.9253 & $3.586 \mathrm{E}+08$ & $2.045 \mathrm{E}+08$ & $5.174 \mathrm{E}+08$ & 0.230 & 78.411 & $<0.0001$ \\
\hline
\end{tabular}

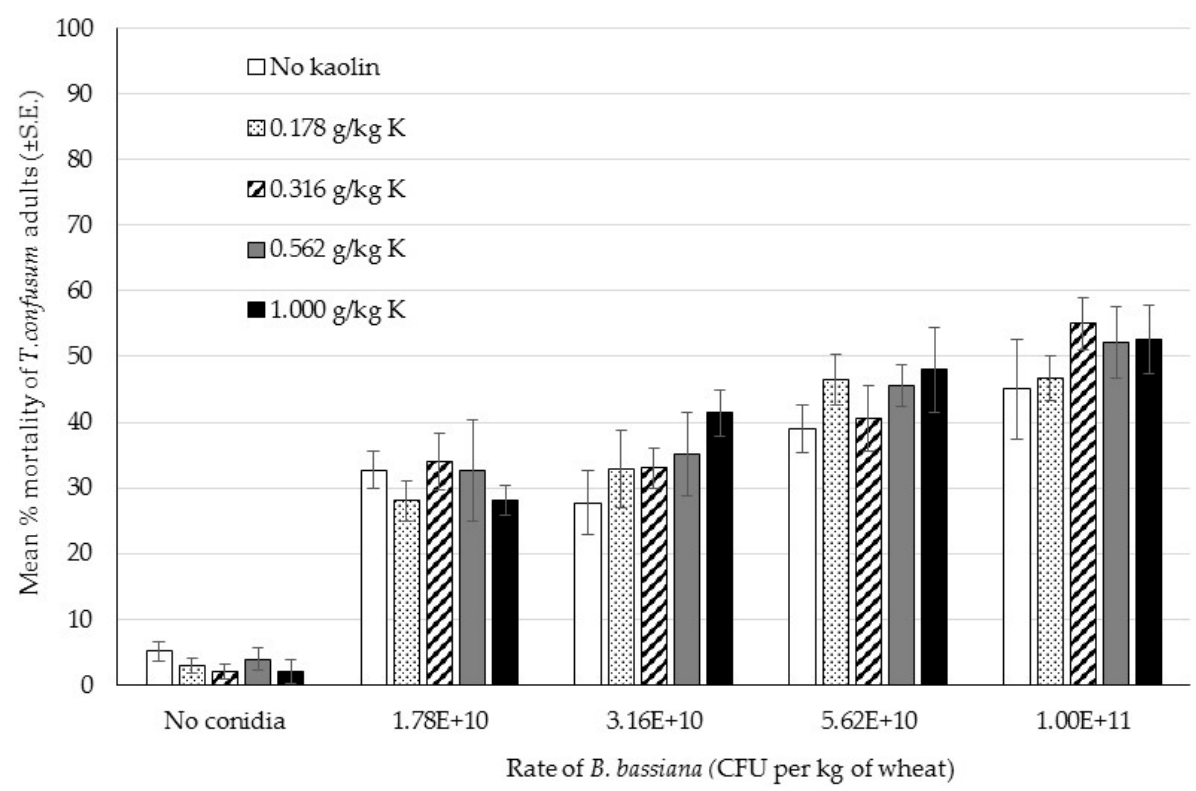

Figure 3. Bioassay 3: Percentage mortality of Tribolium confusum adults exposed to different rates of Beauveria bassiana IMI389521, and different rates of kaolin, after 14 days of exposure (Mean \pm SE). 
Table 3. Results of logistic regression on Tribolium confusum adult mortality data for each rate of kaolin in dose response bioassay 3.

\begin{tabular}{ccccccc}
\hline $\begin{array}{c}\text { Rate of Kaolin } \\
\text { (g per kg of Wheat) }\end{array}$ & $\begin{array}{c}\text { LC50 (CFU per kg } \\
\text { of Wheat) }\end{array}$ & $\begin{array}{c}\text { Lower } \\
\text { Bound 95\% }\end{array}$ & $\begin{array}{c}\text { Upper } \\
\text { Bound 95\% }\end{array}$ & $\mathbf{R}^{\mathbf{2}}$ & $\chi^{\mathbf{2}}$ & $\boldsymbol{p}$-Value \\
\hline 0 & $1.99 \mathrm{E}+11$ & $8.86 \mathrm{E}+10$ & $3.48 \mathrm{E}+15$ & 0.013 & 7.008 & 0.008 \\
0.178 & $1.07 \mathrm{E}+11$ & $6.72 \mathrm{E}+10$ & $5.04 \mathrm{E}+11$ & 0.020 & 10.885 & 0.001 \\
0.316 & $8.97 \mathrm{E}+10$ & $5.83 \mathrm{E}+10$ & $3.28 \mathrm{E}+11$ & 0.020 & 10.612 & 0.001 \\
0.562 & $8.60 \mathrm{E}+10$ & $5.65 \mathrm{E}+10$ & $2.92 \mathrm{E}+11$ & 0.021 & 11.352 & 0.001 \\
1.000 & $7.23 \mathrm{E}+10$ & $5.07 \mathrm{E}+10$ & $1.58 \mathrm{E}+11$ & 0.025 & 13.459 & $>0.001$ \\
\hline
\end{tabular}

No statistical analysis was carried out on the larval mortality data since adult emergence was zero, or close to zero $\left(0.2 \% \pm 0.18 \%\right.$ at $1.78 \times 10^{10}$ with $0.562 \mathrm{~g}$ kaolin per $\mathrm{kg}$ wheat), in all the treatment groups that contained fungus. In contrast, the adult emergence from the treatment groups that contained no fungus were $53 \%$ (no kaolin) and $47 \%$ (kaolin at $0.562 \mathrm{~g}$ per $\mathrm{kg}$ wheat). From this data it is not clear whether kaolin has any effect, either on its own or combined with fungus. However, the data does clearly indicate that the fungus is effective at preventing adult emergence when the larvae are treated with $\geq 1.78 \times 10^{10} \mathrm{CFU}$ per $\mathrm{kg}$ wheat.

\subsection{Bioassay 4: Dose Response of S. granarius and the Effect of Temperature}

The data clearly indicate that at each time point the level of mortality increased with increasing concentration of B. bassiana (Figure 4), and that for each rate of fungus the mortality was increased in the presence of kaolin. The concentration of B. bassiana $\left(F_{(3,312)}=212.46, p<0.0001\right)$ and the presence of kaolin $\left(F_{(1,311)}=251.68, p<0.0001\right)$ were found to be significant effects, as was the effect of temperature $\left(F_{(1,316)}=61.53, p<0.0001\right)$ and exposure period $\left(F_{(1,315)}=121.35, p<0.0001\right)$. Moreover, significant interactions were found between time and kaolin $\left(F_{(1,302)}=11.93, p=0.0006\right)$, fungus and kaolin $\left(F_{(3,299)}=3.77, p=0.011\right)$, and time $\times$ fungus $\times$ kaolin $\left(F_{(3,293)}=2.77, p=0.042\right)$. In addition to the mortality increasing with fungal rate and kaolin inclusion, mortality was significantly higher at the second time point. Mortality was also significantly higher at $25^{\circ} \mathrm{C}$ than at $15{ }^{\circ} \mathrm{C}$. The significant interaction between time, fungal rate, and kaolin indicates that the degree of synergy between kaolin and fungus was dependent on time. There were bigger differences between formulations with and without kaolin at the second time point than at the first.

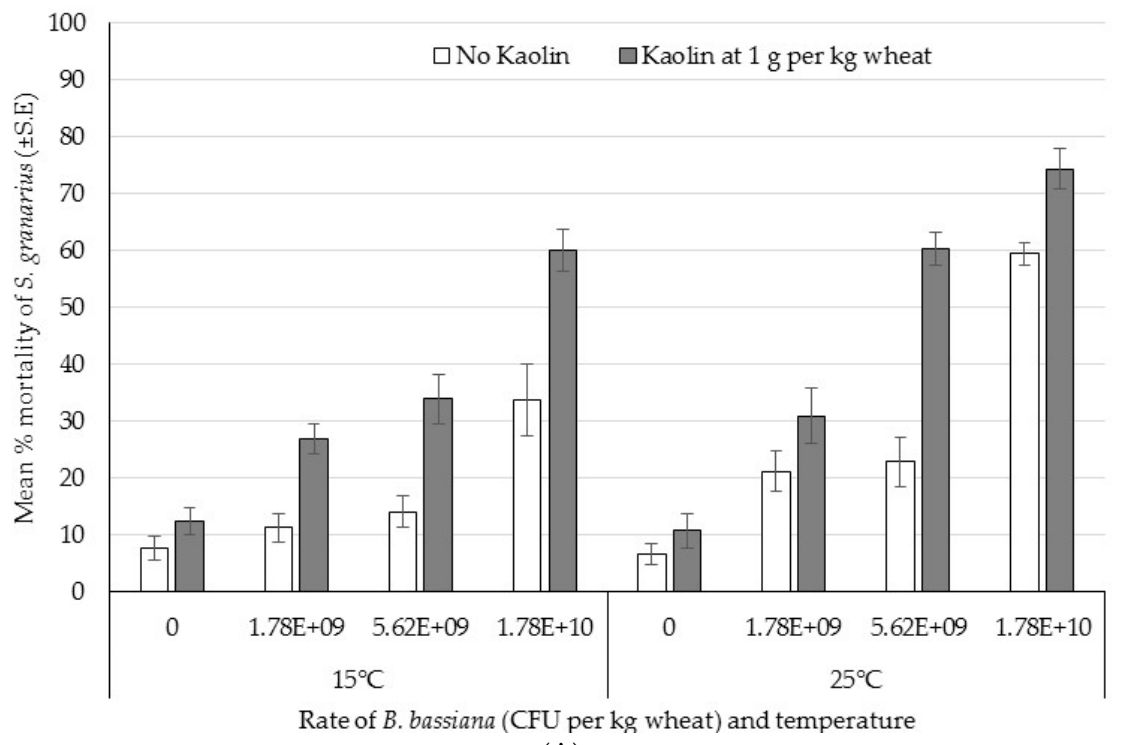

(A)

Figure 4. Cont. 


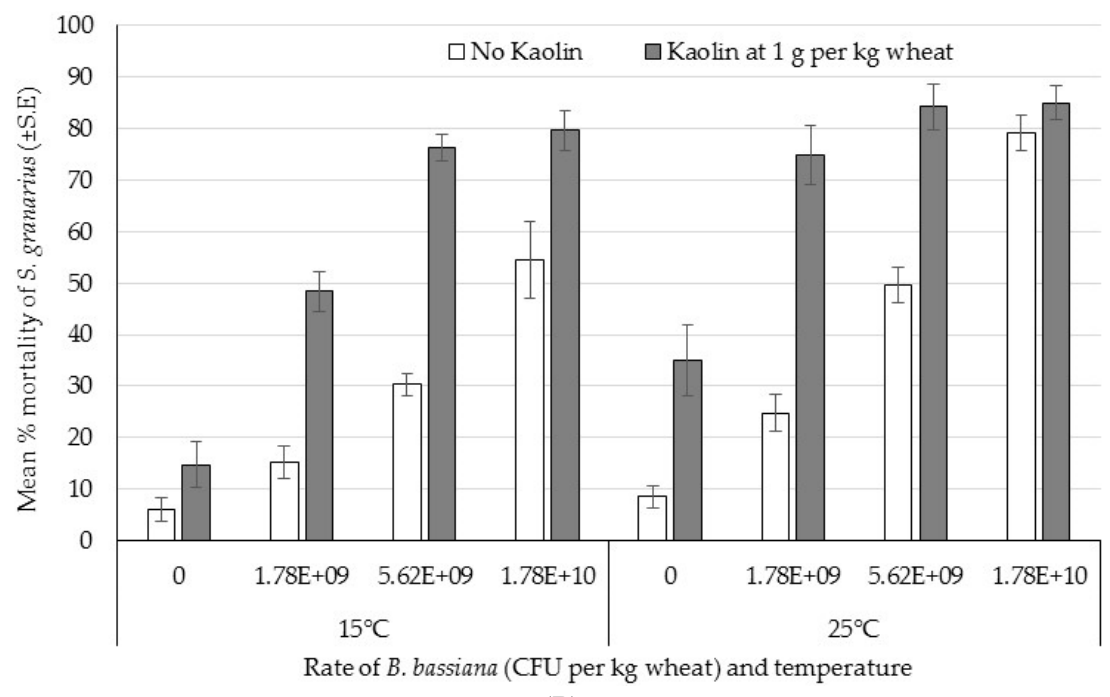

(B)

Figure 4. Bioassay 4: Percentage mortality of Sitophilus granarius exposed to different rates of Beauveria bassiana IMI389521 in colony forming units (CFU) per $\mathrm{kg}$ of wheat, with and without kaolin at $1 \mathrm{~g}$ per $\mathrm{kg}$ of wheat, at 15 or $25^{\circ} \mathrm{C}$ after (A) 14 days and (B) 28 days of exposure (Mean $\pm \mathrm{SE}$ ).

Not all of the data were a good fit for the probit model (Table 4), particularly if kaolin had been included in the treatment. At 14 days, including kaolin lowered the LC50 at both temperatures. At 28 days and $15^{\circ} \mathrm{C}$, the LC50 was also lowered when kaolin was included but no LC50 was calculated for the $25^{\circ} \mathrm{C}$ data since all dose responses exceeded $50 \%$ mortality when kaolin was included. The LC50 at both time points was lower at $25^{\circ} \mathrm{C}$ than at $15{ }^{\circ} \mathrm{C}$.

Table 4. Results of logistic regression on Sitophilus granarius adult mortality data for each treatment group (time $\times$ temp. $\times$ kaolin) in dose response bioassay 4 .

\begin{tabular}{|c|c|c|c|c|c|c|c|c|}
\hline $\begin{array}{l}\text { Days after } \\
\text { Treatment }\end{array}$ & $\begin{array}{c}\text { Temperature } \\
\left({ }^{\circ} \mathrm{C}\right)\end{array}$ & Kaolin & $\begin{array}{c}\text { LC50 (CFU per kg } \\
\text { of Wheat) }\end{array}$ & $\begin{array}{c}\text { Lower } \\
\text { Bound 95\% }\end{array}$ & $\begin{array}{c}\text { Upper } \\
\text { Bound 95\% }\end{array}$ & $\mathbf{R}^{2}$ & $x^{2}$ & $p$-Value \\
\hline \multirow{4}{*}{14} & \multirow{2}{*}{15} & No & $4.21 \mathrm{E}+10$ & $2.48 \mathrm{E}+10$ & $2.54 \mathrm{E}+11$ & 0.180 & 33.154 & $<0.0001$ \\
\hline & & Yes & $1.12 \mathrm{E}+10$ & $8.22 \mathrm{E}+09$ & $1.73 \mathrm{E}+10$ & 0.081 & 40.373 & $<0.0001$ \\
\hline & \multirow{2}{*}{25} & No & $1.44 \mathrm{E}+10$ & $1.11 \mathrm{E}+10$ & $2.08 \mathrm{E}+10$ & 0.117 & 54.743 & $<0.0001$ \\
\hline & & Yes & $4.28 \mathrm{E}+09$ & $3.24 \mathrm{E}+09$ & $5.45 \mathrm{E}+09$ & 0.087 & 62.332 & $<0.0001$ \\
\hline \multirow{4}{*}{28} & \multirow{2}{*}{15} & No & $1.49 \mathrm{E}+10$ & $1.13 \mathrm{E}+10$ & $2.22 \mathrm{E}+10$ & 0.123 & 54.862 & $<0.0001$ \\
\hline & & Yes & $1.51 \mathrm{E}+09$ & $7.09 \mathrm{E}+08$ & $2.32 \mathrm{E}+09$ & 0.036 & 33.985 & $<0.0001$ \\
\hline & \multirow{2}{*}{25} & No & $5.49 \mathrm{E}+09$ & $4.46 \mathrm{E}+09$ & $6.62 \mathrm{E}+09$ & 0.149 & 103.483 & $<0.0001$ \\
\hline & & Yes & \multicolumn{6}{|c|}{ No analysis possible, all responses $>50 \%$} \\
\hline
\end{tabular}

\section{Discussion}

Our studies clearly demonstrate that the addition of even relatively low doses of kaolin clay powder can enhance the efficacy of $B$. bassiana against some adult stored grain beetle pests. Synergistic effects were demonstrated for both $O$. surinamensis and S. granarius, though not T. confusum. Despite the low susceptibility of $T$. confusum adults, the larvae were highly susceptible to the fungus with close to zero emergence of adult $T$. confusum when larvae were treated with a range of fungal rates, with or without the kaolin. In none of the assays was kaolin by itself effective, which is consistent with information from published literature [10] that as a standalone product, efficacy is only observed at rates $\geq 5 \mathrm{~g}$ per $\mathrm{kg}$ of wheat, and the highest rate tested in the present study was $1.9253 \mathrm{~g}$ per $\mathrm{kg}$ of wheat. Synergistic effects are observed when the effect of two actives taken together is greater than the sum of their separate effect at the same doses. When $O$. surinamensis were treated with a range of fungal and kaolin rates, the mortality in the combined treatment was greater than the sum 
of the mortality in the corresponding kaolin alone and fungus alone treatment groups when kaolin was $\geq 0.96 \mathrm{~g}$ per $\mathrm{kg}$ of wheat. Similarly, in most treatment groups, the mortality of $S$. granarius was greater in the combined formulation (kaolin at $1 \mathrm{~g}$ per $\mathrm{kg}$ of wheat) than the sum of the mortality caused by kaolin alone or the corresponding fungal rate applied alone. The results indicate synergistic rather than additive effects for these two insect species and are in accordance with results reported by Lord (2001) [29], Akbar et al. (2004) [30], and Sabbour et al. (2012) [6] when the inert dust DE was combined with entomopathogenic fungal spores for control of stored grain beetles and moths. However, as far as we are aware, the current study represents the first demonstration that such a synergistic effect can occur when kaolin is combined with an entomopathogenic fungus.

It is not clear why inert dusts may synergise the effect of entomopathogenic fungi. Akbar et al. (2004) [30] found that the presence of DE increased the conidial attachment of B. bassiana on the cuticle of T. castaneum larvae, but Lord (2001) [29] reported no significant increase in the case of $R$. dominica larvae. Samodra \& Ibraham [32] observed that the waxy layer of the insect's integument was abraded and removed by the kaolin, which had allowed greater conidial attachment and fungal penetration through the insect exoskeleton. The increased water loss through the insect cuticle as a result of abrasion and absorption of cuticular waxes by inert dusts may result in favourable conditions for spore germination or increase the stress levels of the insect making them more susceptible to fungal infection. A combination of factors may result in their suitability as co-formulants.

The degree of synergism may be highly dependent on temperature and relative humidity. At higher temperatures, water loss is increased and insects are more mobile and so take up more particles on their cuticles [6,15]. Inert dusts are, therefore, generally more effective at higher temperatures. However, there is a threshold at which the activity of the fungus begins to decline. Vassilakos et al. (2006) [36] found that B. bassiana (Naturalis ${ }^{\circledR}$ SC, Troy Biosciences, Phoenix, AZ, USA) was more effective against $R$. dominica and $S$. oryzae at $26^{\circ} \mathrm{C}$ than at $30^{\circ} \mathrm{C}$. Athanassiou and Steenberg (2007) [25] reported that the efficacy of B. bassiana decreased when temperature increased from 25 to $30^{\circ} \mathrm{C}$. The optimum temperature for B. bassiana conidial germination and vegetative growth is reported as around $25^{\circ} \mathrm{C}[37,38]$. In the present study, temperature was found to be a significant factor affecting mortality of $S$. granarius, with greater mortality at the higher temperature of $25^{\circ} \mathrm{C}$. This is to be expected as fungal germination is increased with increasing temperature (up to a threshold) and, like DE, the effect of kaolin may be increased at higher temperatures. There was no significant interaction between temperature and the presence or absence of kaolin; the degree of synergism was not greater at $25^{\circ} \mathrm{C}$ than at $15^{\circ} \mathrm{C}$. Alterations in the relative humidity were not investigated in the present study, but there may be complex interactions since water stress would increase under lower relative humidity. Inert dusts are more efficacious at lower moisture levels, however, it is not clear how this relationship may change if combined with an entomopathogenic fungus. The effectiveness of $B$. bassiana under different relative humidity varies widely with some studies indicating better efficacy at reduced moisture levels $[39,40]$ and others reporting that the fungus may be less active in drier conditions [41,42]. In the present study, the efficacy with the fungus alone was actually greater at $1 \times 10^{10}$ conidia per $\mathrm{kg}$ of wheat in bioassay 1 , with around $80 \%$ mortality, than at the higher concentration of $1.7 \times 10^{10} \mathrm{CFU}$ per $\mathrm{kg}$ of wheat in bioassay 2 where mortality was $<50 \%$. Although the units of concentration are different, there are usually fewer CFU than conidia per $\mathrm{kg}$ of wheat since conidia per $\mathrm{kg}$ is the total number of spores present and CFU is the total viable spores present. The main difference between the two studies was that the relative humidity was uncontrolled and consequently lower in bioassay 1 , supporting the findings by Lord $[39,40]$ that activity of $B$. bassiana, at least in the case of this isolate, may be better at reduced moisture levels.

The degree of synergism may also depend on the concentrations of each active. Vassilakos et al. (2006) [36] found some additive and some negative effects between B. bassiana and the DE product SilicoSec ${ }^{\circledR}$ (Biofa GmbH, Münsingen, Germany) against adults of S. oryzae and R. dominica, which appeared to be concentration-dependent. At the lowest fungal rates, the addition of DE did not increase the fungal efficacy, and in some cases caused a detrimental effect, and at the highest fungal 
rates, an additive effect was more often recorded. In the present study, the lowest kaolin rate of $0.0963 \mathrm{~g}$ per $\mathrm{kg}$ of wheat had neither an additive nor detrimental impact on the mortality caused by the fungus against $O$. surinamensis; both higher rates of kaolin had synergistic effects. In the Sitophilus bioassay, no detrimental effects of including kaolin were observed, all effects were either additive or synergistic, and these effects were observed at both temperatures and time points.

The susceptibility of the insects to the fungus and the degree of synergism between kaolin and the fungus is clearly dependent on the species and life stage tested. In the present study, in terms of adult insects, we found O. surinamensis to be the most susceptible, followed by S. granarius, and then T. confusum was the most resistant. This order of susceptibility is in agreement with previous work on this isolate [33]. Resistance of adult Tribolium sp. to entomopathogenic fungal infection has been previously reported [30,43,44]. Wakefield (2006) [33] demonstrated, using scanning electron microscopy, that quantitative and qualitative differences in adherence and germination of fungal conidia could be observed between a susceptible species, O. surinamensis, and the resistant T. confusum. At each of the post-treatment periods, O. surinamensis had a greater number of fungal conidia adhering to the cuticle, and the greater adherence appeared to be related to the greater number of setae, particularly on the ventral abdomen, of O. surinamensis compared to T. confusum. Lord (2007c) [45] showed that $T$. castaneum was more susceptible under desiccation stress. Desiccation stress may be achieved by including an inert dust such as kaolin. However, in the present study, against T. confusum adults, the kaolin had no synergistic effect on the fungus at the levels tested, and it was not possible to determine any effects on the larvae since all rates tested resulted in close to $0 \%$ emergence of adult beetles. As a result of this, no LC50 was calculated for larvae. Lower rates were not tested on larvae. At day 14 post treatment, an acceptable level of efficacy (>70\%) against $S$. granarius was only achieved at the highest rate of $1.78 \times 10^{10} \mathrm{CFU}$ per $\mathrm{kg}$ of wheat with kaolin at $1 \mathrm{~g}$ per $\mathrm{kg}$ of wheat, although lower rates were effective on $O$. surinamensis. As the formulation must contain a dose that will be efficacious against all the target species, a rate of $1.78 \times 10^{10} \mathrm{CFU}$ per $\mathrm{kg}$ of wheat with kaolin at around $1 \mathrm{~g}$ per $\mathrm{kg}$ of wheat would ensure acceptable efficacy against adult $O$. surinamensis, S. granarius and the larval stage of T. confusum.

It has previously been observed that Tribolium sp. larvae are more susceptible to entomopathogenic fungi than the adult life stage [26,30], an effect which has been shown to synergise with the presence of DE [30]. Kavallieratos et al. (2006) [27] recovered very few progeny of T. confusum in wheat treated with $M$. anisopliae and no progeny production was recorded when DE was included. Tribolium sp. larvae feed and develop in the external part of the kernels, thus, the chance of encountering fungal conidia is increased compared to that of the adults. In terms of susceptibility to inert dusts, like the fungi, the larvae are much more susceptible to DE than the adults $[18,46]$. In order to better understand the relationship between kaolin and B. bassiana IMI389521 and the potential for any synergy, lower rates of fungus would need to be tested.

It has been demonstrated that the inert dust kaolin can have synergistic effects when combined with an entomopathogenic fungus and results in much higher levels of efficacy against stored grain beetles than would otherwise be possible with the isolate alone. This has been previously demonstrated for an alternative mineral earth powder, DE. Kaolin may convey certain advantages over the use of $\mathrm{DE}$ since it is softer and may be less likely to negatively impact processing machinery. While the kaolin demonstrated little effectiveness on T. confusum adults, the isolate tested, IMI389521, already demonstrated high levels of efficacy on the larvae, which may in fact be a better target. By targeting the larvae rather than the adults there is a reduced possibility that adults will emerge, mate, and lay eggs before the fungal infection has been able to take effect. It would be worthwhile to screen the isolate and co-formulant kaolin on the life stages of other grain beetles, and, perhaps, other important grain pests such as moths and psocids. 


\section{Conclusions}

Kaolin is a widely available and relatively inexpensive material. It is already known as a non-synthetic control product with insect repellent properties, and it is currently used in particle film technology for protection of a wide variety of agricultural crops $[47,48]$. This research has now demonstrated the potential for kaolin as a co-formulant for entomopathogenic fungal control, in this case, for use in stored grain. By synergizing the effect of the fungus, the co-formulant kaolin may overcome the lower levels of efficacy that are perceived as a barrier to the widespread adoption of microbial control agents in storage systems.

Acknowledgments: This research was part-funded by the UK's Agritech Catalyst fund, administered by Innovate UK, the UK's innovation agency.

Author Contributions: Clare Storm, Adam Nunn and Freya Scoates conceived, designed and performed the experiments; Clare Storm and Freya Scoates analysed the data; Aoife Dillon reviewed the experimental designs and the manuscript; Olivier Potin manufactured and quality controlled the test materials; Clare Storm wrote the paper.

Conflicts of Interest: The authors declare no conflict of interest.

\section{References}

1. Pimentel, D. World resources and food losses to pests. In Ecology and Management of Food Industry Pests; Gorham, J.R., Ed.; Association of Official Analytical Chemists: Arlington, MA, USA, 1991; pp. 5-11.

2. Lord, J.C.; Campbell, J.F.; Sedlacek, J.D.; Vail, P.V. Application and evaluation of entomopathogens for managing insects in stored products. In Field Manual of Techniques in Invertebrate Pathology; Lacey, L.A., Kaya, H.K., Eds.; Springer: Dordrecht, The Netherlands, 2007; pp. 677-693.

3. Cherry, A.J.; Abalob, P.; Hell, K. A laboratory assessment of the potential of different strains of the entomopathogenic fungi Beauveria bassiana (Balsamo) Vuillemin and Metarhizium anisopliae (Metschnikoff) to control Callosobruchus maculatus (F.) (Coleoptera: Bruchidae) in stored cowpea. J. Stored Prod. Res. 2005, 41, 295-309. [CrossRef]

4. Cherry, A.J.; Aba, P.; Hell, K.; Korie, S. Farm-scale trials to compare the entomopathogenic fungus Beauveria bassiana with pirimiphos methyl plus deltamethrin and essential oil of lemon grass for protection of stored cowpea against Callosobruchus maculatus (Coleoptera: Bruchidae). Ann. Appl. Biol. 2007, 151, 1-10. [CrossRef]

5. Cox, P.D.; Wakefield, M.E.; Price, N.; Wildey, K.B.; Chambers, J.; Moore, D.; Aquino de Muro, M.; Bell, B.A. The Potential Use of Insect-Specific Fungi to Control Grain Storage Pests in Empty Grain Stores. Available online: https:/ / cereals.ahdb.org.uk/media/363584/pr341-final-project-report.pdf (accessed on 19 July 2016).

6. Sabbour, M.M.; Abd-El-Aziz, S.E.; Sherief, M.A. Efficacy of three entomopathogenic fungi alone or in combination with diatomaceous earth. J. Plant Prot. Res. 2012, 52, 359-363. [CrossRef]

7. Dal Bello, G.; Padin, S.; Lastra, C.L.; Fabrizio, M. Laboratory evaluation of chemical-biological control of the rice weevil (Sitophilus oryzae L.) in stored grains. J. Stored Prod. Res. 2001, 37, 77-84. [CrossRef]

8. Moino, A.; Alves, S.B.; Pereira, R.M. Efficacy of Beauveria bassiana (Bal.) Vuilemin isolates for control of stored-grain pests. J. Appl. Entomol. 1998, 122, 301-305. [CrossRef]

9. Ebeling, W. Sorptive dusts for pest control. Ann. Rev. Entomol. 1971, 16, 123-158. [CrossRef] [PubMed]

10. Subramanyam, B.; Roesli, R. Inert Dusts. In Alternatives to Pesticides in Stored-Product IPM; Subramanyam, B., Hagstrum, D., Eds.; Springer: New York, NY, USA, 2000; pp. 321-380.

11. Allen, S. Integration of inert dust into control of storage pests in bulk grain in storage in Australia. In Proceedings of the International Conference Controlled Atmosphere and Fumigation in Stored Products, Fresno, CA, USA, 29 October-3 November 2000; pp. 279-284.

12. Banks, J.; Fields, P.G. Physical Methods for Insect Control in Stored-Grain Ecosystems. In Stored-Grain Ecosystems; Jayas, D.S., White, N.D.G., Muir, W.E., Eds.; Marcel Dekker: New York, NY, USA, 1995; pp. 353-409.

13. Golob, P. Current status and future perspectives for inert dusts for control of stored product insects. J. Stored Prod. Res. 1997, 33, 69-79. [CrossRef] 
14. Arthur, F.H. Toxicity of diatomaceous earth to red flour beetles and confused flour beetles (Coleoptera: Tenebrionidae): Effects of temperature and relative humidity. J. Econ. Entomol. 2000, 93, 526-532. [CrossRef] [PubMed]

15. Fields, P.; Korunic, Z. The effect of grain moisture content and temperature on the efficacy of diatomaceous earths from different geographical locations against stored-product beetles. J. Stored Prod. Res. 2000, 36, 1-13. [CrossRef]

16. Subramanyam, B.; Swanson, C.L.; Madamanchi, N.; Norwood, S. Effectiveness of Insecto ${ }^{\circledR}$, a new diatomaceous earth formulation in suppressing several stored grain insect species. In Proceedings of the 6th International Working Conference on Stored Product Protection, Canberra, Australia, 17-23 April 1994; Volume 2, pp. 650-659.

17. Timlick, B.; Fields, P.G. A comparison of the effect of two diatomaceous earth formulations on Plodia interpunctella (Hübner) and the effect of different commodities on diatomaceous earth efficacy. In Proceedings of the 10th International Working Conference on Stored Product Protection, Estoril, Portugal, 27 June-2 July 2010.

18. Vayias, B.J.; Athanassiou, C.G. Factors affecting efficacy of the diatomaceous earth formulation SilicoSec ${ }^{\circledR}$ against adults and larvae of the confused beetle Tribolium confusum Du Val (Coleoptera: Tenebrionidae). Crop Prot. 2004, 23, 565-573. [CrossRef]

19. Korunic, Z.; Fields, P.G.; Kovacs, M.I.P.; Noll, J.S.; Lukow, O.M.; Demianyk, C.J.; Shibley, K.J. The effect of diatomaceous earth on grain quality. Postharvest Biol. Technol. 1996, 9, 373-387. [CrossRef]

20. Korunic, Z.; Cenkowski, S.; Fields, P. Grain bulk density as affected by diatomaceous earth and application method. Postharvest Biol. Technol. 1998, 13, 81-89. [CrossRef]

21. Murray, H.H. Traditional and new applications for kaolin, smectite, and palygorskite: A general overview. Appl. Clay Sci. 2000, 17, 207-221. [CrossRef]

22. Arthur, F.H.; Puterka, G.J. Evaluation of kaolinite-based particle films to control Tribolium species (Coleoptera: Tenebrionidae). J. Stored Prod. Res. 2002, 38, 341-348. [CrossRef]

23. Mahmoud, A.E.M.; El-Sebai, O.A.; Shahen, A.A.; Marzouk, A.A. Impact of kaolin-based particle film dusts on Callosobruchus maculatus (F.) and C. chinenesis (L.) after different storage periods of treated broad bean seeds. Julius Kühn-Institut 2010, 425, 638-646.

24. Golob, P.; Webley, D.J. The Use of Plants and Minerals as Traditional Protectants of Stored Products; Tropical Products Institute: London, UK, 1980.

25. Athanassiou, C.G.; Steenberg, T. Insecticidal effect of Beauveria bassiana (Balsamo) Vuillemin (Ascomycota: Hypocreales) in combination with three diatomaceous earth formulations against Sitophilus granarius (L.) (Coleoptera: Curculionidae). Biol. Control 2007, 40, 411-416. [CrossRef]

26. Michalaki, M.P.; Athanassiou, C.G.; Kavallieratos, N.G.; Batta, Y.A.; Balotis, G.N. Effectiveness of Metarhizium anisopliae (Metschinkoff) Sorokin applied alone or in combination with diatomaceous earth against Tribolium confusum Du Val larvae: Influence of temperature, relative humidity and type of commodity. Crop Prot. 2006, 25, 418-425. [CrossRef]

27. Kavallieratos, N.G.; Athanassiou, C.G.; Michalaki, M.P.; Batta, Y.A.; Rigatos, H.A.; Pashalidou, F.G.; Balotis, G.N.; Tomanović, Ž.; Vayias, B.J. Effect of the combined use of Metarhizium anisopliae (Metschinkoff) Sorokin and diatomaceous earth for the control of three stored-product beetle species. Crop Prot. 2006, 25, 1087-1094. [CrossRef]

28. Michalaki, M.P.; Athanassiou, C.G.; Steenberg, T.; Buchelos, C.T. Effect of Paecilomyces fumosoroseus (Wise) Brown and Smith (Ascomycota: Hypocreales) alone or in combination with diatomaceous earth against Tribolium confusum Jacquelin du Val (Coleoptera: Tenebrionidae) and Ephestia kuehniella Zeller (Lepidoptera: Pyralidae). Biol. Control 2007, 40, 280-286.

29. Lord, J.C. Dessicant dusts synergise the effect of Beauveria bassiana (Hyphomycetes: Moniliales) on stored-grain beetles. J. Econ. Entomol. 2001, 94, 367-372. [CrossRef] [PubMed]

30. Akbar, W.; Lord, J.C.; Nechols, J.R.; Howard, R.W. Diatomaceous earth increases the efficacy of Beauveria bassiana against Tribolium castaneum larvae and increased conidial attachment. J. Econ. Entomol. 2004, 97, 273-280. [CrossRef] [PubMed]

31. Samodra, H.; Ibrahim, Y. Effectiveness of selected entomopathogenic fungi in packed rice grain at room temperature against Corcyra cephalonica Stainton. ASEAN J. Sci. Technol. Dev. 2006, 23, 183-192. 
32. Samodra, H.; Ibrahim, Y. Effects of dust formulation of three entomopathogenic fungal isolates against Sitophilus oryzae (Coleopteran: Curculionidae) in rice grain. J. Biosains 2006, 17, 1-7.

33. Rees, D. Insects of Stored Grain: A Pocket Reference; CSIRO Publishing: Collingwood, Australia, 2007.

34. Wakefield, M.E. Factors affecting storage insect susceptibility to the entomopathogenic fungus Beauveria bassiana. In Proceedings of the 9th International Working Conference on Stored Product Protection, Campinas, São Paulo, Brazil, 15-18 October 2006.

35. Wakefield, M.E.; Moore, D.; Luke, B.; Taylor, B.; Storm, C.G.; Collins, D.A.; Grammare, P.; Potin, O. Progress in the development of a biopesticide for the structural treatment of grain stores. Julius Kühn-Institut 2010, $425,760-765$.

36. Vassilakos, T.N.; Athanassiou, C.G.; Kavallieratos, N.G.; Vayias, B.J. Influence of temperature on the insecticidal effect of Beauveria bassiana in combination with diatomaceous earth against Rhyzopertha dominica and Sitophilus oryzae on stored wheat. Biol. Control 2006, 38, 270-281. [CrossRef]

37. Ekesi, S.; Maniania, N.K.; Ampong-Nyarko, K. Effect of Temperature on Germination, Radial Growth and Virulence of Metarhizium anisopliae and Beauveria bassiana on Megalurothrips sjostedti. Biocontrol Sci. Technol. 1999, 9, 177-185. [CrossRef]

38. Luz, C.; Fargues, J. Temperature and moisture requirements for conidial germination of an isolate of Beauveria bassiana, pathogenic to Rhodnius prolixus. Mycopathologia 1997, 138, 117-125. [CrossRef] [PubMed]

39. Lord, J.C. Low humidity, moderate temperature, and desiccant dust favor efficacy of Beauveria bassiana (Hyphomycetes: Moniliales) for the lesser grain borer, Rhyzopertha dominica (Coleoptera: Bruchidae). Biol. Control 2005, 34, 180-186. [CrossRef]

40. Lord, J.C. Enhanced efficacy of Beauveria bassiana for red flour beetle with reduced moisture. J. Econ. Entomol. 2007, 100, 1071-1074. [CrossRef]

41. Huafeng, L.; Meizhen, F.; Zengzhi, L.; Cui, H. Pathogenic effect of Beauveria bassiana infected on Dendrolimus under different temperature and humidity. Chin. J. Appl. Ecol. 1998, 9, 195-200.

42. Luz, C.; Fargues, J. Dependence of the entomopathogenic fungus, Beauveria bassiana, on high humidity for infection of Rhodnius prolixus. Mycopathologia 1999, 146, 33-41. [CrossRef] [PubMed]

43. Padin, S.; Dal Bello, G.; Fabrizio, M. Grain loss caused by Tribolium castaneum, Sitophilus oryzae and Acanthoscelides obtectus in stored durum wheat and bean treated with Beauveria bassiana. J. Stored Prod. Res. 2002, 38, 69-74. [CrossRef]

44. Rice, W.C.; Cogburn, R.R. Activity of the entomopathogenic fungus Beauveria bassiana (Deuteromycota: Hypomycetes) against three coleopteran pests of stored grain. J. Econ. Entomol. 1999, 92, 691-694. [CrossRef]

45. Lord, J.C. Desiccation increases the efficacy of Beauveria bassiana for stored-grain pest insect control. J. Stored Prod. Res. 2007, 43, 535-539. [CrossRef]

46. Shayestah, N.; Ziaee, M.; Safaralizadeh, M.H. Insecticidal efficacy of diatomaceous earth against Tribolium castaneum (Herbst) (Coleoptera: Tenebrionidae). In Proceedings of the 9th International Working Conference on Stored Product Protection, Passo Fundo, RS, Brazil, 15-18 October 2006; pp. 1212-1217.

47. Glenn, D.M.; Puterka, G.; Vanderzwet, T.; Bryers, T.; Feldhake, C. Hydrophobic particle films: A new paradigm for the suppression of arthropod pests and plant diseases. J. Econ. Entomol. 1999, 92, 751-771. [CrossRef]

48. Puterka, G.J.; Glenn, D.M.; Sekatowski, D.G.; Unruh, T.R.; Jones, S.K. Progress towards liquid formulations of particle films for insect and disease control in pear. Environ. Entomol. 2000, 29, 329-339. [CrossRef]

(C) 2016 by the authors; licensee MDPI, Basel, Switzerland. This article is an open access article distributed under the terms and conditions of the Creative Commons Attribution (CC-BY) license (http://creativecommons.org/licenses/by/4.0/). 